\title{
NOTICE \\ Publication Manual of the American Psychological Association (3rd. ed.)
}

In January 1984, the six journals published by the Psychonomic Society will begin generally to follow the format and style conventions of the recently published Third Edition of the Publication Manual of the American Psychological Association.

\section{ANNOUNCEMENT \\ Sponsorship of Papers for the Bulletin of the Psychonomic Society}

To encourage the publication of a greater number and a broader range of articles in the Bulletin of the Psychonomic Society, the Publications Committee of the Psychonomic Society has decided to reinstate the policy (discontinued in 1977) of publishing sponsored articles.

A manuscript submitted by a nonmember or nonmembers should be accompanied by a letter from a member in good standing agreeing to the sponsorship. When the paper is published, the sponsor's name will appear immediately below the name(s) of the author(s). (Please note that the usual limit of four printed pages will apply.)

Nonmembers are encouraged to take advantage of the opportunity for quick publication, and members are urged to participate in the Society's endeavor to expand the Bulletin and to broaden its scope. 